\title{
Developing a digital toolkit to enhance the communication of health claims: the Health Claims Unpacked project
}

Article

Accepted Version

Lockyer, S., Ryder, C., Jaworska, S. ORCID:

https://orcid.org/0000-0001-7465-2245, Benelam, B. and Jones, R. (2020) Developing a digital toolkit to enhance the communication of health claims: the Health Claims Unpacked project. Nutrition Bulletin, 45 (4). pp. 432-443. ISSN 14719827 doi: https://doi.org/10.1111/nbu.12469 Available at https://centaur.reading.ac.uk/94904/

It is advisable to refer to the publisher's version if you intend to cite from the work. See Guidance on citing.

To link to this article DOI: http://dx.doi.org/10.1111/nbu.12469

Publisher: Wiley-Blackwell

All outputs in CentAUR are protected by Intellectual Property Rights law, including copyright law. Copyright and IPR is retained by the creators or other copyright holders. Terms and conditions for use of this material are defined in the End User Agreement. 


\section{CentAUR}

Central Archive at the University of Reading

Reading's research outputs online 


\title{
Emerging Research - Developing a Digital Toolkit to Enhance the Communication of Health Claims, 'the Health Claims Unpacked' project
}

\author{
Lockyer, $\mathbf{S}^{1}$; Ryder, $C^{2}$; Jaworska $\mathrm{S}^{2}$; Benelam, $\mathbf{B}^{\mathbf{1}}$ \& Jones, $\mathbf{R}^{\mathbf{2}}$. \\ ${ }^{1}$ British Nutrition Foundation, UK \\ ${ }^{2}$ Department of English Language \& Applied Linguistics, University of Reading, UK
}

\begin{abstract}
Consumer understanding and acceptance of health claims is influenced by a variety of factors including personal knowledge and familiarity with the information, characteristics of the product (such as the ingredients) and the way the claim is presented (e.g. wording and visual aids such as symbols). The official wording of authorised EU health claims is set by the European Commission (EC), though there is some flexibility, in that food companies can change the wording to aid consumer understanding of the claim as long as the original meaning is retained and the modified version does not mislead. An EIT Food-funded project with the consumer facing title 'Health Claims Unpacked', consists of an international consortium aiming to develop a digital toolkit to investigate consumers' responses to health claims and aid their understanding thereof. Developed firstly in English (and now also in other EU languages such as German, French and Polish), the toolkit is informed by research in linguistics, design, nutrition science, technology and behavioural economics as well as focus groups with consumers and interviews with the food industry. The format of the toolkit is an interactive web app comprising activities which are used to gather data regarding consumers' responses to different kinds of linguistic, semiotic (signs and symbols) and marketing cues related to health claims and how these cues impact their understanding of the relationship between nutrients/food components and health, trust in the message and willingness to pay for products. The data will be used to provide information on the preferences of different demographic groups on the wording of health claims and to provide recommendations for stakeholders aiming to enhance the communication of health claims on food and drink labels.
\end{abstract}

\section{Introduction}

Within the EU, nutrition and health claims relating to food and drink products, which may be found on product packaging and advertisements, are regulated under EU law (Regulation No 1924/2006). Although the UK is no longer a member of the EU, during the transition period (i.e. until the end of 2020), all existing EU laws will continue to apply in the UK and, after this time, the UK Nutrition and Health Claims Committee (UKNHCC) is expected to advise on the scientific evidence behind nutrition and health claim applications and give scientific opinions to the relevant UK government authorities (UK government 2020). According to the Nutrition and Health Claims Regulation, “'claim' means any message or representation...including pictorial, graphic or symbolic representation, in any form, which states, suggests or implies that a food has particular characteristics" (page 5) and more specifically, "a 'health claim' means any claim that states, suggests or implies that a relationship exists between a food category, a food or one of its constituents and health" (page 6) (EC (European Commission) 2006). The Regulation states that "[i]t is important that claims on foods can be understood by the consumer and it is appropriate to protect all consumers from misleading claims." (page 3). By 'consumer', the Regulation "takes as a benchmark the average consumer, who is reasonably well-informed and reasonably observant and circumspect, taking into account social, cultural 
and linguistic factors." (page 3). Consumer interest in, attitudes towards and understanding of health claims have been a focus of research undertaken across Europe (Cavaliere et al. 2015; Hodgkins et al. 2019; Hung \& Verbeke 2019; Hieke et al. 2015; Carrillo et al. 2014; Stancu et al. 2017; Bilman et al. 2012) and this article aims to outline the background and rationale for an EIT Food-funded project in this area, with the consumer facing title 'Health Claims Unpacked'.

\section{Consumer perceptions of health claims}

Factors affecting consumer understanding and acceptance of health claims are summarised in Figure 1. Overall, whether a consumer understands and accepts a health claim can depend on a variety of factors. This includes the context, such as whether the food component being highlighted is normally present within that particular food; the type of product or claim; the framing (e.g. 'positive' or 'negative' wording); familiarity of the claim or brand; personal beliefs and personal relevance (e.g. whether or not someone has a health condition that is related to the claim) (Hieke \& Grunert 2018; Hung \& Verbeke 2019). Evidence has been reported of a 'halo effect' - i.e. that consumers sometimes over-interpret health benefits communicated by health claims, assuming that a product carrying a claim is generally nutritionally superior (van buul \& Brouns 2015; Bröring \& Khedkar 2018) and a 'magic bullet' effect in which consumers attribute inappropriate health benefits to a product bearing a claim (Hieke \& Grunert 2018). In addition, while many consumers have been found to interpret health claims in line with the scientific evidence behind the claim (Bilman et al. 2012), others only make vague interpretations e.g. that the product is 'healthy' (or indeed has other attributes that are unrelated to the claim), while the detail of the claim is not understood (Grunert et al. 2011). 'Soft' information that is presented on the packaging (e.g. indicating that a product is 'traditional') can be more effective at implying a health benefit than the 'hard' scientific information contained within a health claim (Aschemann-Witzel \& Grunert 2015). There is evidence that factors such as the size of the label, the placement of the information on the packaging, where and when the product is purchased and the other products surrounding the product on the shelf can also influence the perception of nutrition and health claims (van buul \& Brouns 2015).

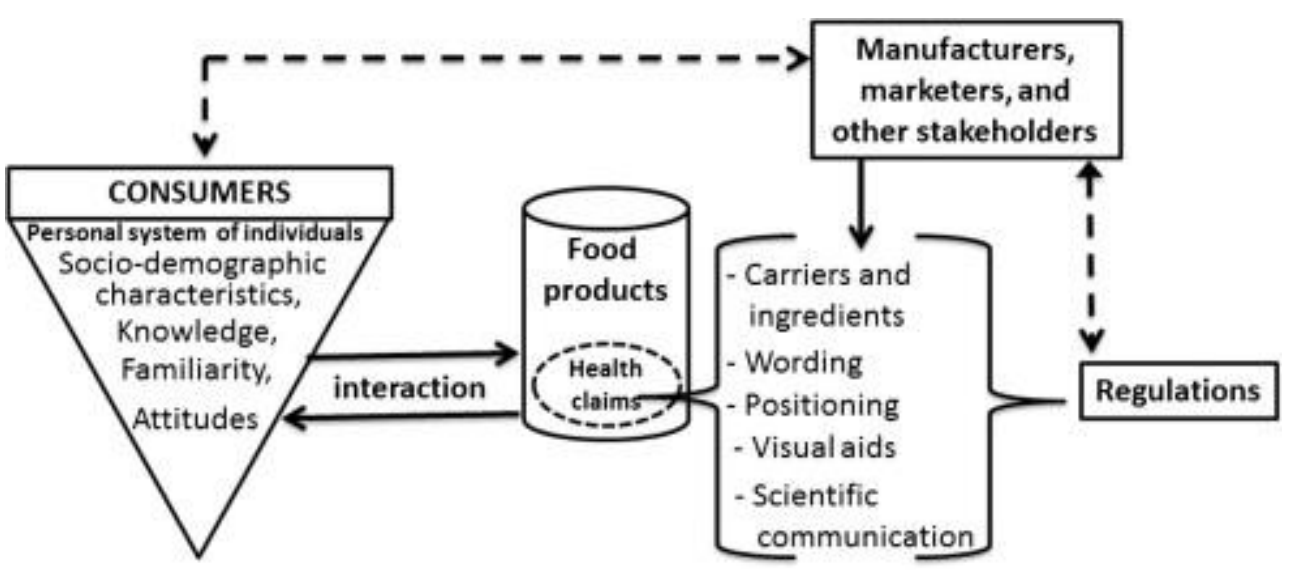

Figure 1: Factors influencing consumers' understanding of health claims. Source: (Nocella \& Kennedy 2012) License number for figure replication: 4787060592753. 
Most research investigating consumer responses to health claims has focused on written or textual claims, even though the Regulation also covers visual claims (pictures, graphics and symbols) (Purnhagen et al. 2016). Other packaging elements that can draw attention to a product (such as colours and images) provide a background for interpreting claims and can influence perceived nutritional content, acting as 'nudges' (van Herpen \& van Trijp 2018). Indeed, some research suggests that images can imply health benefits (Klepacz et al. 2016; Groeppel-Klein et al. 2017) (perhaps influenced by the perceived 'healthiness' of the brand overall), though a study carried out in Denmark found that colour schemes, brand names and front-of-pack imagery had no effect on consumer perceptions of 'healthiness' (Orquin \& Scholderer 2015). It has been proposed that pictorial representations of health claims may be useful for conveying information to low literacy consumers (Viswanathan et al. 2009).

\section{Wording of health claims}

Research suggests that the wording of claims and interpretation by consumers is a concern for the food industry (Bröring et al. 2017). A survey of $54 \mathrm{EU}$ food companies conducted in 2014 found that wording of claims was the biggest challenge related to the Nutrition and Health Claims Regulation reported by companies (Khedkar et al. 2017). According to the Regulation, "The use of nutrition and health claims shall only be permitted if the average consumer can be expected to understand the beneficial effects as expressed in the claim" and "in order to ensure that health claims are truthful, clear, reliable and useful to the consumer in choosing a healthy diet, the wording and the presentation of health claims should be taken into account in the opinion of the European Food Safety Authority [EFSA] and in the subsequent authorisation procedure". As part of its assessment of claims, EFSA considers whether the wording suggested by the applicant reflects the scientific evidence (EFSA Panel on Dietetic Products Nutrition and Allergies 2016). In situations where this is found to be the case, the European Commission (EC) then takes the final decision as to whether the wording is understandable and meaningful 'to the average consumer' (though, arguably, the level of understanding is likely to vary across a wide spectrum among different consumers). For authorised claims, the final official wording of the claim can be viewed within the online register of nutrition and health claims made on foods (EC (European Commission) 2019). The register also records submitted claims that did not receive approval. It is expected that the official wording is used on products (Buttriss 2015), though the wording of some claims may not appeal from a marketing perspective (Bröring \& Khedkar 2018) and may even create negative perceptions in consumers' minds in some cases (e.g. health claims which stipulate that particular fibre types contribute to an increase in faecal bulk). There is some flexibility, in that food companies can change the wording provided that the aim is to help consumer understanding, taking into account factors such as linguistic and cultural variations and the target population, as long as the original meaning is retained and the modified version does not mislead (e.g. by exaggerating the claim). Indeed, the impact of changing the wording of claims on perceived health benefits has been noted (Bilman et al. 2012) though not comprehensively investigated and little is known about how demographic, linguistic and cultural factors influence the perceptions of health claims and adapted wording provided by food manufacturers.

Seventeen Member States agreed an informal set of general principles linked to the wording of claims in 2012 (Department of Health and Social Care 2013). One concerns use of the word 'normal' which appears in the English version of many health claims (e.g. potassium contributes to the maintenance of normal blood pressure), advising that this word should be retained in adapted wording and should not be replaced by another term or removed (although in some linguistic versions of the Regulation in other languages, words such as 'proper' or 
'healthy' are used instead of 'normal', as discussed later). For the UK, further advice is provided by the Advertising Standards Authority (Advertising Standards Authority 2015) and such advice is also available in some of the other Member States including Belgium, Italy and the Netherlands (de Boer et al. 2015).

Member States are individually responsible for local enforcement of the Nutrition and Health Claims Regulation and it is evident that processes including interpretation of the Regulation, the level of guidance provided to industry and monitoring the use of claims can vary (de Boer et al. 2015), meaning that wording of a claim that is acceptable in one Member State may be unacceptable on an identical product in another (Buttriss 2015). Furthermore, the trigger by which a food business is investigated at a national level can vary; for example, in the UK an investigation may be triggered should a single complaint be received. Media coverage of investigations into health claims communications may reduce consumer trust in the health claims process (Buttriss 2015).

Some studies suggest that consumers find detailed scientific terminology confusing and prefer shorter claims, though preferences do differ (Nocella \& Kennedy 2012; van Herpen \& van Trijp 2018; van buul \& Brouns 2015). For example, in a study ( $n=295)$ comparing five versions of a beta-glucan claim, the official claim wording was understood to the highest extent and rewording (to make the claim shorter and less technical) or adding words was actually found to reduce understanding (Stancu et al. 2017). A series of studies employing eye tracking methodology found that subjects were more likely to avoid a health claim (which was the longest and most complex statement) than a generic claim or a nutrition claim ${ }^{1}$ on packaging, and gave more visual attention to health claims that contained familiar wording (GroeppelKlein et al. 2017). Indeed, the highest rated finding from the EU-funded CLYMBOL project (assessed by European stakeholders) was that communication of health claims should be kept simple, clear and scientifically sound yet phrased without using overly complex scientific language/regulatory jargon in order to be meaningful, since consumers favour health claims with shorter and less complex messages (Hung et al. 2019). However, research suggests that using more familiar (rather than specific) words can create confusion as this may lead to activation and retrieval of additional information stored in consumers' memories, rather than a limited amount of focused information (Anderson 1983). This can exaggerate the claim by conjuring up assumptions that are not directly related to the claimed benefit, since previous knowledge has an impact on the inferences that people make (Lähteenmäki et al. 2010; Andrews et al. 1998). The current list of authorised claims contains a spectrum of descriptions for nutrients, food components and health effects that arguably ranges from simple to complex and more or less familiar to the average consumer (e.g. 'zinc contributes to the maintenance of normal skin' versus, for example, 'olive oil polyphenols contribute to the protection of blood lipids from oxidative stress'). Ultimately, when it comes to the wording of claims, simplicity will lose out to the requirement for scientific accuracy in some cases.

\footnotetext{
${ }^{1}$ A 'nutrition claim' is any claim which states, suggests or implies that a food has particular beneficial nutritional properties due to the nutrients it contains, contains in reduced or increased proportions or does not contain EC (European Commission) (1990) Council Directive of 24 September 1990 on nutrition labelling for foodstuffs.https://eurlex.europa.eu/LexUriServ/LexUriServ.do?uri=CONSLEG:1990L0496:20081211:EN:PDF (accessed 6 April 2020). Examples of nutrition claims include 'low fat', 'sugars-free', 'high in fibre' and 'source of iron'.
} 
There are aspects of the wording of health claims that can present cognitive difficulties for readers. Many examples of official claim wording exhibit two features that are common in scientific language: high 'lexical density' and frequent use of 'nominalisation' (Halliday \& Martin, 1993). Lexical density refers to how 'tightly' content words are packed within a clause. The greater the lexical density, the greater the cognitive load on the reader. For example, sentence (a) below, taken from the EU database of approved claims, has a lexical density of 6 content words per clause, whereas a version of this claim taken from a manufacturer's package has a lexical density of 4 words per clause. Of course, it is often the case that reducing lexical density also reduces the amount or specificity of the information in the clause.

a) Selenium contributes to the protection of cells from oxidative stress (6)

b) Selenium contributes to antioxidant activity (4)

A related feature of official claim wording that makes health claims potentially more difficult to process is 'nominalisation'. Nominalisation is when a verbal process is turned into a noun. In the phrase 'the protection of cells from oxidative stress' in sentence (a) the verb 'protect' is turned into the noun 'protection'. Nominalisations require readers to 'unpack' the construction to figure out what the action is and what is being acted upon. Sentence (b), on the other hand, eliminates nominalisations.

Another potential issue with the wording of health claims within the EU is that it is sometimes difficult to attain exact equivalence from one European language to another. The approved health claims are available in English and Member States, in which English is not the main language, have to translate them into local languages (though translations do exist within documents available on the EC website (EC (European Commission) 2009b; EC (European Commission) 2012b)). Each language has different grammatical and lexical resources for formulating scientific claims, which are embedded in the local scientific discourse. This means that the translated health claims differ from the original English wording and, even if direct equivalents exist, the preference might be given to an alternative. For example, most of the approved health claims in English include the word 'normal' as in:

c) Vitamin C contributes to the normal function of the immune system (EC (European Commission) 2012a)

Although the word 'normal' exists in Polish, the translated health claims almost always use the alternative lexical item 'prawidłowy', which means 'proper' or 'correct'. Also, the verb 'contributes to', which is the dominant verb in English health claims is often changed in Polish claims to 'help', as in:

d) Witamina C pomaga w prawidłowym funkcjonowaniu układu odpornościowego (EC (European Commission) 2012b)

(translation: Vitamin C helps with proper functioning of the immune system)

Overall, the meaning of the Polish translation differs from the official wording in English in that the wording emphasises more strongly the 'healthiness' and 'special-ness' of the nutrient as opposed to the more neutral expression in English, which simply states an 'ordinary' relationship between the nutrient and the immune system. 
A similar pattern can be noticed in some of the German official translations that use 'gesund' ('healthy') instead of 'normal'. For example, the official wording in English:

e) Calcium and vitamin D are needed for normal growth and development of bone in children (EC (European Commission) 2009a)

has been translated to:

f) Kalzium und Vitamin D werden für ein gesundes Wachstum und eine gesunde Entwicklung der Knochen bei Kindern benötigt. (EC (European Commission) 2009b)

(translation: Calcium and vitamin D are needed for healthy growth and for healthy development of bones in children)

The use of the word 'gesund' stresses 'healthy' as opposed to 'normal' growth and development. The modulations in meaning may contribute to different perceptions and attitudes regarding health claims on food packaging across the EU, possibly with some consumers (e.g. Polish, German) seeing them as more beneficial and useful than, for example consumers who have this information only available in English.

\section{Differences in perceptions of health claims between European countries}

A survey of $>5,000$ consumers conducted as part of the CLYMBOL project found that from a list of 17 health claims, the claims ranked the most familiar and the claims ranked the least familiar were largely similar among 10 European countries (United Kingdom, Germany, The Netherlands, Spain, Slovenia, Czech Republic, France, Denmark, Greece and Lithuania) (Hung $\&$ Verbeke 2019). The highest level of health claim use while food shopping was reported by participants in Spain and Greece and the lowest was among consumers in the Netherlands. Motivation to process health claims (derived from having an interest in healthy eating and feeling a need for health-related information), rather than ability to process health claims was found to determine use of health claims, and this was similar across all 10 countries, regardless of the different histories of use of health claims and regulation prior to 2006 between countries (Hung et al. 2017).

A survey carried out in Nordic countries $(n=4612)$ indicated that consumers inferred that products with health claims were less 'natural' and less tasty (Lähteenmäki et al. 2010). Conversely, a study carried out in Denmark $(n=204)$ found that the presence of health claims on pack did not affect perceived 'healthiness' or sensory expectation but did significantly negatively affect purchase intentions (Orquin \& Scholderer 2015). Interestingly in the same study, nutrition claims increased perceived 'healthiness' and sensory expectation but did not affect purchasing intentions. A study of 1504 consumers reported differences in proneness to over-interpretation of claims, which was more likely among UK consumers than French, Italian and German consumers (Bilman et al. 2012) and the impact of health claims on purchasing behaviour has also been shown to differ between countries, with German and Finnish consumers more likely and Italian consumers less likely to buy products with health claims $(\mathrm{n}=2385)$ (Shepherd et al. 2012).

There may also be cultural differences in the way pictorial representations on food packaging are perceived (Ares et al. 2011; Saba et al. 2010). In a study carried out in Finland, Germany, 
Italy and the UK $(n=2392)$, the presence of a disease risk reduction claim (i.e. claims related to reducing a risk factor in the development of a disease, such as blood cholesterol) on products increased consumers' perceptions of healthiness across all four countries, whereas functional claims (i.e. claims relating to the growth, development and functions of the body; psychological and behavioural functions; or weight control) (EC (European Commission) 2020) increased this perception only in consumers in the UK and Finland (Saba et al. 2010). Reduction of disease risk claims increased willingness to buy among German and Finnish consumers, whereas British consumers were more willing to buy products with functional claims (Saba et al. 2010). Conversely, Italian consumers were more willing to buy products devoid of written health claims or pictorial representations implying healthiness (i.e. 'natural' (e.g. leaves on a branch) or 'medical' symbols (e.g. a medical cross)) and perceived foods without any pictorial representations as healthier (Saba et al. 2010). Consumers in Finland, Germany and the UK perceived foods with 'natural' symbols on the label as healthy, and consumers from these three countries were more willing to buy such products, but only Finnish consumers were more willing to buy products bearing 'medical' symbols (Saba et al. 2010). Overall in this study, written health claims were found to have a stronger influence on respondents' perception of healthiness and on the likelihood of purchasing the products than pictorial health claims (Saba et al. 2010). However, in a study carried out in Spain and Denmark $(\mathrm{n}=296)$ symbols had more influence on both product appeal and 'convincingness' than textual claims (Carrillo et al. 2014). This study reported that different connotations were attached to symbols (olives, a heart with a stethoscope, a man running and mechanical gears) between the two countries, though the overall perceptions were similar. In addition, the Danish consumers had a more negative perception of health claims compared to the Spanish consumers.

Overall, the perception, understanding and use of both written and pictorial health claims appears to be dependent on many factors, both individual and cultural. Consumer understanding of scientific wording, translation of approved wording into different languages, as well as country-specific differences in consumer interpretation, all require consideration by food businesses and may present barriers to the use of health claims (Gilsenan 2011; Bröring et al. 2017; Bremmers \& van der Meulen 2013). Consumer trust and acceptance of health claims is important since one of the intended functions of claims is to enable consumers to make healthier choices. Therefore, the presentation of health claims in a way that both resonates with consumers and complies with the Regulation is key for the food industry as well as potentially important for public health if their use results in positive behaviour change.

\section{'Health Claims Unpacked' project outline}

A project entitled 'Developing a Digital Toolkit to Enhance the Communication of Scientific Health Claims', with the consumer-facing title 'Health Claims Unpacked' has been funded by EIT-Food and started in January 2019 (EIT Food 2020b). The project brings together a unique combination of researchers and professionals with expertise in linguistics, information design, behavioural economics, health, nutrition and computer science, working in partnership with manufacturers, retailers, NGOs and food start-ups. The project partners are The University of Reading, Technische Universität München (TUM), Food Maestro and the British Nutrition Foundation. The aim of the project is to develop a digital toolkit (in the form of an interactive web app), firstly in English and later in other EU languages (German, French, Polish) informed by research in linguistics, design, nutrition science, technology studies and behavioural economics to enhance the communication of health claims among consumers, businesses and 
policy makers. The web app will be used to gather and analyse data on consumers' responses to different kinds of linguistic, semiotic (signs and symbols) and marketing cues related to health claims and how these cues affect their understanding of the relationship between the nutrient, food component or food and health, trust in the message and willingness to pay for products. The project, which is now in its second year, is aligned with EIT Food's strategic objectives (EIT Food 2020a), with specific objectives as follows:

\section{- Overcome low consumer trust \& enhance transparency}

In the first year, the project team used consumer focus groups and engagement with a variety of stakeholders to look at which attributes of health claims affect consumer understanding. These attributes were built into the design of the interactive web app in order to explore what kind of wordings consumers prefer and, on this basis, how to improve the communication of health claims.

In the second year of the project, this activity is engaging with a wider European user base to explore consumers' understanding of health claims further and how this is affected by cultural and linguistic factors. This will feed into the further development of the web app in other European languages to enhance understanding, trust and transparency around health claims in the EU.

\section{- Fragmented supply chain - build a consumer-centric connected food system}

This activity links the pillars of the EIT knowledge triangle (business, education and research) using a prosumerist approach (i.e. design and production by consumers) in which end users of health claims contribute to the design of effective communication of health claims. The outputs of this process will provide information for stakeholders along the entire supply chain including food manufactures, regulators and policy makers.

- Skills gap: educate to engage, innovate and advance

The main output of the activity will be an interactive web app available in selected European languages (English, German, French, Polish, Romanian and Hungarian) The web app is designed to not only gather data about the determinants of consumer understanding of health claims, but also (in the process) inform stakeholders involved in the production of health claims. In the second year, the expanded web app will gather data about the determinants of European consumer understanding of health claims and provide customised education opportunities for consumers in different EU cultural contexts and help manufacturers to translate and adapt claims so that they are both within the constraints of the Nutrition and Health Claims Regulation and understandable to consumers. Results will be shared via events aimed at different stakeholders.

\section{Year 1 project activities}

\section{Work package 1 - Mapping of the Health Claims Supply Chain in Europe \& Establishing a Marketing Plan}

Current use of health claims on UK product packaging was assessed and these observations were supplemented with qualitative interviews with food industry members to discuss their experiences with using health claims. In particular, companies were asked if they had faced any issues around consumer understanding and wording to explore whether or not the challenges in relation to this particular aspect of the Regulation reported in previous research 
persist and are widespread. Interviews are ongoing, though discussions to date have uncovered generally negative experiences in dealing with the wording of health claims, with challenges such as the extra cost in time and resources that companies must spend on agreeing the best approach between different teams within the organisation (such as Marketing, Legal, Science $\&$ Nutrition and Management) and a desire for clearer guidelines from legislators often described.

UK focus groups with consumers from different demographic groups were conducted to gather views on health claims used on food labels, including how these are presented linguistically and visually, with the help of commercially available products (including breakfast cereals, fruit juices, milk, bread, tea, canned beans and frozen vegetables) as visual aids, and whether/how this information is used to assess product 'healthiness'. Four demographics took part in focus groups: students aged 18-25 years, health-conscious men aged 30-45 years, parents (of children aged 7-8 years) responsible for food purchases for the family and people aged over 50 years concerned about their health. Key linguistic, visual and marketing attributes and expectations were identified based on themes emerging from these focus groups, which were used to feed into the design of the interactive web app. A mistrust in health claims that are presented on pack using the format of a shorter claim followed by an asterisk, linked to the full official claim wording located elsewhere on the pack, was expressed by all focus group participants. In addition, it became clear that there were significant differences between the demographic groups and their attitudes towards food shopping: students and health-conscious men each demonstrated a generally positive attitude toward most of the products used as visual prompts, with a recognition that there were only a few that they would consider unhealthy, whereas parents and over-50s generally took the view that there were only a few healthy options among a majority of products they would never buy. For parents, a key driver for purchasing habits was the health of their family; amongst the over-50s, many participants articulated dismay at frequently changing 'rules' regarding what is considered healthy, and a high level of scepticism for health claims displayed on products that they were used to classing as unhealthy. More detailed results will be published in a separate paper.

An online social media presence for the project was established through two campaigns run on EIT Food's 'FoodUnfolded' Instagram account (in September and November 2019), as well as content on FoodUnfolded.com and Healthclaimsunpacked.co.uk. The different platforms were used to engage with consumers and other stakeholders to generate interest and discussion, with the end goal of recruiting subjects to complete the activities within the interactive web app (see Work Package 2). The campaigns aimed to introduce the topic of health claims to consumers, for example by providing information on how they are regulated and presented (e.g. explaining the scientific names for different vitamins alongside images of foods that are a source of these nutrients), as well as gauging consumer awareness, understanding of and trust in health claims through the use of quizzes and opinion polls carried out through Instagram, using specific examples of authorised claims. For example, a poll asking the question "Do you think claims on food labels are based on solid scientific evidence?" received 440 votes, with $79 \%$ selecting the option "It's just marketing" and only $21 \%$ selecting "Definitely" as their response. Points raised during the UK focus groups were also used to shape the contents of the campaigns.

\section{Work Package 2: Development of a Consumer-Centric Recommender Digital Toolkit}

An interactive web app (unpackinghealthclaims.eu) has been developed with online activities designed to inform consumers on the topic of health claims and also aiming to determine how consumers interact with health claims on different kinds of products when the claims are 
worded differently or appear in combination with different graphical elements (font, colour, symbols). For example, after being provided with information around recognised relationships between food components and health, such as alpha-linolenic acid and blood cholesterol levels (as per authorised health claims), users are asked which products (from a set of examples bearing health claims presented differently) they would buy if looking for particular health attributes. Users are also asked to design their own food packet, choosing their preferred wording and location for a health claim. A prototype website was tested for suitability by employing the use of focus groups conducted at the University of Reading, using the same four demographic groups as for the focus groups looking at food products, and usability was tested at TUM. A qualitative usability assessment was conducted, consisting of a pre-test with one testing subject (student, female) and an actual test with three participants (two female, one male, all students) whose usage of the prototype was screen recorded. Test subjects were recorded in audio and video during the usage in order to provide feedback and the consecutive focus group discussion in which strengths and limitations of the interface and software, along with any suggestions, were collected.

\section{Work Packages 3-5: Collection and Analysis of Data, Formulation and Validation of Key Practice Guidelines in Collaboration with Stakeholders, Produce Recommendations for European Policymakers and Regulators}

Registration for the interactive web app was encouraged via social media communications, emails sent to volunteer databases and a video on the healthclaimsunpacked.co.uk home page. Participants provided demographic information, as well as information regarding health conditions and health goals, in order to stratify the data. At the time of writing, 422 consumers had signed up to the English language version of the interactive web app and produced 680 cocreated health claims. Preliminary analysis has been carried out based on data from the first 196 participants who completed the activities in 2019 and supplied demographic information. For one of the activities, participants were asked: to construct the wording of four different health claims by selecting from a list of alternative words and phrases; to choose where to position a health claim on food packaging and to choose whether or not to display an accompanying icon (e.g. a tick symbol, a plus symbol or a benefit-specific icon such as a bone for a calcium claim). For all four claims, the official wording was chosen by a very small proportion of participants. The vast majority of consumers did not select the word 'normal' and opted for alternatives instead such as 'healthy'; the phrase 'contributes to' was also unpopular. These initial findings suggest that official claim wordings are dispreferred by consumers. In addition, more common names for nutrients were favoured above scientific names (e.g. 'vitamin B7' and 'omega-3' were preferred to 'biotin' and 'alpha-linolenic acid' respectively). The use of benefit-specific icons alongside health claims was much preferred, with the use of a tick being the second most popular choice. There were no obvious preferences in terms of the location of health claims on pack. Data collection using the English language version of the interactive web app is ongoing and detailed results will be published in a separate paper.

In addition, an online survey consisting of 39 multiple choice questions was conducted to investigate consumers' understanding of, attitudes towards and trust in health claims. At the time of writing, 667 consumers had completed the survey. Preliminary findings based on a sample of 352 participants revealed that when asked to rank a health claim worded differently 
in order of preference, the official wording was the least popular and in general, preference increased with a greater number of changes to the official wording. This supports the initial findings obtained from the interactive web app.

A stakeholder workshop was held at the University of Reading in December 2019, which was attended by representatives from the food industry and regulatory bodies as well as consumers. The event consisted of providing background information on the project, discussion of results from the focus groups and preliminary findings from the interactive web app, a panel discussion regarding points generated by the results and a breakout session to generate recommendations for all stakeholders based on findings from the project. The recommendations from the breakout session can be summarised as follows:

1. Policy makers should put into place processes for gathering feedback from consumers about the comprehensibility of the language of health claims.

2. The EC and/or national authorities should provide clearer guidelines as to how the language of health claims can and cannot be adapted in order to create more consistency throughout jurisdictions and clarity for manufacturers.

3. Those involved in setting or communicating health claims should recognise that the way in which consumers interpret claims may differ from the way scientists do, and vice-versa.

4. Stakeholders involved in nutrition and health claims should engage in consumerfacing educational activities in order to enhance consumer awareness of the regulation of health claims.

5. The EC and/or national authorities should consider creating a resource for consumers to find out about the scientific evidence behind different claims.

The recommendations generated at the stakeholder workshop will be taken alongside data from the interactive web app, the focus groups with consumers and the interviews with industry to produce a list of recommendations for policy makers for improving the communication of health claims so that the wording used is understandable by consumers and culturally appropriate.

\section{Year 2 project activities}

The aim of the second year of the project is to roll out the interactive web app (produced in English in year 1) to Germany, France and Poland. These three countries represent just over $40 \%$ of the EU population (European Union 2020), and France and Germany have the largest consumer bases in the EU (The World Bank 2020). The languages spoken in these countries represent three distinct language families that are representative of the linguistic diversity of the EU. Each language possesses lexical and grammatical similarities with other languages in their family, allowing for some linguistic generalisations to be made.

\section{Work Package 1: Researching cross-cultural and cross-linguistic responses to health claims}

Focus groups, in a similar format to those carried out in the UK in year 1 but adapted to be culturally appropriate, have been conducted in France, Germany and Poland to investigate consumer attitudes towards health claims in those countries. Local organisations have been 
employed to run the focus groups and the food products used as stimuli have been selected based on local knowledge and expertise. In addition, food manufacturers operating in Germany, France and Poland are currently being interviewed regarding their experiences in using health claims in order to ascertain any differences between countries e.g. in consumer attitudes towards health claims, local enforcement of the Regulation and how these and any other factors affect the way that manufacturers use (or choose not to use) health claims on pack within these settings.

\section{Work Package 2: Development of three adapted versions of the toolkit based on focus group results and integration of resources into FoodUnfolded}

Three new, culturally appropriate versions of the digital interactive web app have been developed in German, French and Polish, based on focus group results from the respective countries, to test cross-cultural and cross-linguistic determinants of consumers' responses to claims. The intention is that all four interactive web apps will be integrated into the FoodUnfolded suite of resources, MyFoodPortal.

\section{Work Packages 3-5: Data gathering via the new platforms; Development of manufacturer module; Development of new guidelines and recommendations}

Recruitment of users for the interactive web app will be carried out via social media campaigns and targeted advertising to specific groups of individuals that may have higher interest in health claims (e.g. parents of young children, older adults and individuals with diet-related health conditions such as cardiovascular disease).

Data generated by consumer completion of the activities will provide valuable information on how people from different backgrounds understand health claims and how these claims influence their willingness to purchase particular products. In the second year of the project this information will be used to create a 'Manufacturer Module' that food manufacturers and marketers can use to understand how UK consumers respond to the way health claims are presented on pack. Input is being sought from food manufacturers to usefully shape the format of the interface.

Final guidelines and recommendations produced from the project will be disseminated through social media channels, press releases and communication with relevant stakeholders such as groups representing the food industry.

\section{Conclusions}

The data obtained from the interactive web app to date has already provided invaluable insights into consumer preferences around the wording and presentation of health claims. For example, when presented with a choice, the official wording of health claims appears not to be favoured and when considering icons on pack, consumers appear to prefer those that are relevant to the claim. The rollout of the interactive web app to consumers in other European countries and the development of an interface for the food industry will build significantly upon these results. In addition, the project as a whole has brought together stakeholders of all kinds to discuss issues around the wording of health claims and potential solutions. It is hoped that this research will be used by policy makers involved in the Nutrition and Health Claims Regulation to consider ways in which consumer understanding of the health claims can be better assessed, and 
authorised claims worded in such a way that they are understandable and meaningful for consumers. Ultimately, consumers could benefit from more consideration of their preferences if health claims wording becomes more accessible to them as this could encourage healthier choices and could support greater trust in the information found on food and drinks labels. Project findings may be particularly relevant to the UK, since BREXIT might present opportunities for changes to be made to legislation currently provided by the EU (as well as its interpretation and enforcement), including the Nutrition and Health Claims Regulation. A proposal has been submitted for a third and final year of the project to run in 2021, in which the scope of the Manufacturer Module of the interactive web app is to be greatly expanded, and in which foundations for the marketisation of the Manufacturer Module as a purchasable resource are being laid to ensure its financial sustainability and longevity as a key resource for the food industry across the UK and Europe. In addition, data to ascertain preferences around the wording of health claims among consumers in Romania and Hungary will be collected. The Consortium invites any food manufacturers operating in the UK, France, Germany, Poland, Romania and Hungary interested in contributing towards the project by sharing their experiences in the use of health claims (in confidence), to help shape the Manufacturer Module or to hear about the project findings, to get in touch via https://www.healthclaimsunpacked.co.uk/contact-us.

\section{Acknowledgements}

We would like to thank EIT Food for providing the funding for the project described in this article under the Horizon 2020, the EU Framework Programme for Research and Innovation. We would additionally like to thank our project team members and the Food Unfolded team for their support.

\section{References}

Advertising Standards Authority (2015) Food: Health claims.https://www.asa.org.uk/adviceonline/food-health-claims.html (accessed 5 October 2020)

Anderson JR (1983) A spreading activation theory of memory. Journal of Verbal Learning and Verbal Behavior 22: 261-295.

Andrews JC, Netemeyer RG \& Burton S (1998) Consumer Generalization of Nutrient Content Claims in Advertising. Journal of Marketing 62: 62-75.

Ares G, Piqueras-Fiszman B, Varela P et al. (2011) Food labels: Do consumers perceive what semiotics want to convey? Food Quality and Preference 22: 689-698.

Aschemann-Witzel J \& Grunert KG (2015) Influence of 'soft' versus 'scientific' health information framing and contradictory information on consumers' health inferences and attitudes towards a food supplement. Food Quality and Preference 42: 90-99.

Bilman EM, Kleef Ev, Mela DJ et al. (2012) Consumer understanding, interpretation and perceived levels of personal responsibility in relation to satiety-related claims. Appetite 59: 912-920.

Bremmers HJ \& van der Meulen B (2013) Opportunities, problems and pitfalls of nutrition and health claims. APSTRACT: Applied Studies in Agribusiness and Commerce 7: 97-101.

Bröring S \& Khedkar S (2018) Regulatory Compliance and Company Strategies: The Case of the Nutrition and Health Claims Regulation (EC) No. 1924/2006. In Regulating and Managing Food Safety in the EU: A Legal-Economic Perspective (Bremmers, H. and Purnhagen, K. eds.) Springer International Publishing, Cham, pp. 105-128. 
Bröring S, Khedkar S \& Ciliberti S (2017) Reviewing the Nutrition and Health Claims Regulation (EC) No. 1924/2006: What do we know about its challenges and potential impact on innovation? International journal of food sciences and nutrition 68: 1-9.

Buttriss J (2015) Nutrition and health claims in practice. Nutrition bulletin 40: 211-222.

Carrillo E, Fiszman S, Lähteenmäki L et al. (2014) Consumers' perception of symbols and health claims as health-related label messages. A cross-cultural study. Food Research International 62: 653-661.

Cavaliere A, Ricci EC \& Banterle A (2015) Nutrition and health claims: Who is interested? An empirical analysis of consumer preferences in Italy. Food Quality and Preference 41: 44-51.

de Boer A, Urlings M, Vos E et al. (2015) Enforcement of the Nutrition and Health Claim Regulation. European Food and Feed Law Review 10: 334-344.

Department of Health and Social Care (2013) Update on flexibility of wording for health claims.https://www.gov.uk/government/publications/update-on-flexibility-of-wording-forhealth-claims (accessed 5 October 2020)

EC (European Commission) (1990) Council Directive of 24 September 1990 on nutrition labelling for foodstuffs.https://eurlex.europa.eu/LexUriServ/LexUriServ.do?uri=CONSLEG:1990L0496:20081211:EN:PDF (accessed 6 April 2020)

EC (European Commission) (2006) Regulation (EC) No 1924/2006 of the European Parliament and of the Council of 20 December 2006 on nutrition and health claims made on foods.http://eurlex.europa.eu/legal-content/EN/TXT/PDF/?uri=CELEX:32006R1924\&from=en (accessed 5 October 2020)

EC (European Commission) (2009a) Commission Regulation (EC) No 983/2009 of 21 October 2009 on the authorisation and refusal of authorisation of certain health claims made on food and referring to the reduction of disease risk and to children's development and health (Text with EEA relevance).https://eur-lex.europa.eu/legalcontent/EN/TXT/PDF/?uri=CELEX:02009R0983-20140711\&qid=1591891592126\&from=EN (accessed 5 October 2020)

EC (European Commission) (2009b) [Consolidated text: Commission Regulation (EC) No 983/2009 of 21 October 2009 on the authorisation and refusal of authorisation of certain health claims made on food and referring to the reduction of disease risk and to children's development and health (Text with EEA relevance)] [Document in German].https://eurlex.europa.eu/legal-content/DE/TXT/PDF/?uri=CELEX:02009R098320140711\&qid=1591891592126\&from $=$ EN (accessed 5 October 2020)

EC (European Commission) (2012a) Commission Regulation (EU) No 432/2012 of 16 May 2012 establishing a list of permitted health claims made on foods, other than those referring to the reduction of disease risk and to children's development and health Text with EEA relevance.https://eur-lex.europa.eu/legal-content/EN/TXT/PDF/?uri=CELEX:02012R043220170822\&from=EN (accessed 5 October 2020)

EC (European Commission) (2012b) [Commission Regulation (EU) No 432/2012 of 16 May 2012 establishing a list of permitted health claims made on foods, other than those referring to the reduction of disease risk and to children's development and health Text with EEA 
relevance] [Document in Polish].https://eur-lex.europa.eu/legal-

content/PL/TXT/PDF/?uri=CELEX:32012R0432\&from=EN (accessed 5 October 2020)

EC (European Commission) (2019) EU Register of nutrition and health claims made on foods.https://ec.europa.eu/food/safety/labelling_nutrition/claims/register/public/?event=s earch\# (accessed 5 October 2020)

EC (European Commission) (2020) Health claims.https://ec.europa.eu/food/safety/labelling_nutrition/claims/health_claims_en (accessed 5 October 2020)

EFSA Panel on Dietetic Products Nutrition and Allergies (2016) General scientific guidance for stakeholders on health claim applications. EFSA Journal 14: 4367.

EIT Food (2020a) About EIT Food.https://www.eitfood.eu/about-eit-food (accessed 5 October 2020)

EIT Food (2020b) Developing a Digital Toolkit to Enhance the Communication of Scientific Health Claims.https://www.eitfood.eu/public-engagement/projects/developing-a-digital-toolkit-toenhance-the-communication-of-scientific-health-claims (accessed 5 October 2020)

European Union (2020) EU in figures.https://europa.eu/european-union/about-eu/figures/living_en (accessed 5 October 2020)

Gilsenan MB (2011) Nutrition \& health claims in the European Union: A regulatory overview. Trends in Food Science \& Technology 22: 536-542.

Groeppel-Klein A, Freichel M \& Kliebenstein S (2017) Awareness and Relevance of Health Claims At the Point-Of-Sale. In NA - Advances in Consumer Research Vol. 45 (Ayelet Gneezy, V. G., and Patti Williams ed. Duluth, MN : Association for Consumer Research, pp. 640-640.

Grunert KG, Scholderer J \& Rogeaux M (2011) Determinants of consumer understanding of health claims. Appetite 56: 269-277.

Hieke S \& Grunert KG (2018) Consumers and health claims. In Foods, nutrients and food ingredients with authorised EU health claims Elsevier, pp. 19-32.

Hieke S, Kuljanic N, Wills JM et al. (2015) The role of health-related claims and health-related symbols in consumer behaviour: Design and conceptual framework of the CLYMBOL project and initial results. Nutr Bull 40: 66-72.

Hodgkins CE, Egan B, Peacock M et al. (2019) Understanding How Consumers Categorise Health Related Claims on Foods: A Consumer-Derived Typology of Health-Related Claims. Nutrients 11.

Hung Y, Grunert KG, Hoefkens $C$ et al. (2017) Motivation outweighs ability in explaining European consumers' use of health claims. Food Quality and Preference 58: 34-44.

Hung Y, Hieke S, Grunert KG et al. (2019) Setting Policy Priorities for Front-of-Pack Health Claims and Symbols in the European Union: Expert Consensus Built by Using a Delphi Method. Nutrients 11: 403.

Hung Y \& Verbeke W (2019) Consumer evaluation, use and health relevance of health claims in the European Union. Food Quality and Preference 74: 88-99.

Khedkar S, Bröring S \& Ciliberti S (2017) Exploring the Nutrition and Health Claims Regulation (EC) No. 1924/2006: What is the impact on innovation in the EU food sector? Int J Food Sci Nutr 68: 10-17. 
Klepacz NA, Nash RA, Egan MB et al. (2016) When is an image a health claim? A false-recollection method to detect implicit inferences about products' health benefits. Health Psychol 35: 898-907.

Lähteenmäki L, Lampila P, Grunert K et al. (2010) Impact of health-related claims on the perception of other product attributes. Food Policy 35: 230-239.

Nocella G \& Kennedy O (2012) Food health claims - What consumers understand. Food Policy 37: 571-580.

Orquin JL \& Scholderer J (2015) Consumer judgments of explicit and implied health claims on foods: Misguided but not misled. Food Policy 51: 144-157.

Purnhagen K, van Herpen E \& van Kleef E (2016) The Potential Use of Visual Packaging Elements as Nudges. In Nudging - Possibilities, Limitations and Applications in European Law and Economics (Mathis, K. and Tor, A. eds.) Springer International Publishing, Cham, pp. 197-216.

Saba A, Vassallo M, Shepherd R et al. (2010) Country-wise differences in perception of health-related messages in cereal-based food products. Food Quality and Preference 21: 385-393.

Shepherd R, Dean M, Lampila P et al. (2012) Communicating the benefits of wholegrain and functional grain products to European consumers. Trends in Food Science \& Technology 25: 63-69.

Stancu V, Grunert KG \& Lähteenmäki L (2017) Consumer inferences from different versions of a beta-glucans health claim. Food Quality and Preference 60: 81-95.

The World Bank (2020) Final consumption expenditure (current US\$).https://data.worldbank.org/indicator/NE.CON.TOTL.CD?end=2018\&most_recent_value _desc=false\&start=1960\&view=chart\&year_high_desc=true (accessed 5 October 2020)

UK government (2020) UK Nutrition and Health Claims Committee (UKNHCC) https://www.gov.uk/government/groups/uk-nutrition-and-health-claims-committee\#termsof-reference (accessed 5th October 2020)

van buul VJ \& Brouns FJPH (2015) Nutrition and Health Claims as Marketing Tools. Critical Reviews in Food Science and Nutrition 55: 1552-1560.

van Herpen E \& van Trijp HC (2018) EU Health Claims: A Consumer Perspective. In Regulating and Managing Food Safety in the EU Springer, pp. 89-104.

Viswanathan M, Hastak M \& Gau R (2009) Understanding and Facilitating the Usage of Nutritional Labels by Low-Literate Consumers. Journal of Public Policy \& Marketing 28: 135-145. 